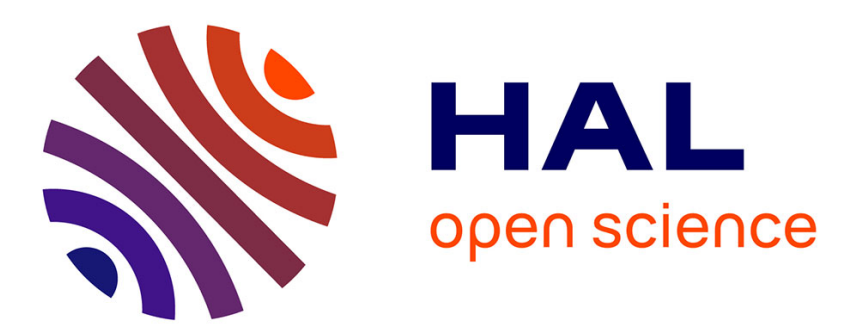

\title{
Behavior modelling and microstructural evolutions of Ti-6Al-4V alloy under hot forming conditions
}

\author{
Vincent Velay, H. Matsumoto, Vanessa Vidal, A. Chiba
}

\section{To cite this version:}

Vincent Velay, H. Matsumoto, Vanessa Vidal, A. Chiba. Behavior modelling and microstructural evolutions of Ti-6Al-4V alloy under hot forming conditions. International Journal of Mechanical Sciences, 2016, 108-109, pp.1-13. 10.1016/j.ijmecsci.2016.01.024 . hal-01384397

\section{HAL Id: hal-01384397 \\ https://hal.science/hal-01384397}

Submitted on 19 Oct 2016

HAL is a multi-disciplinary open access archive for the deposit and dissemination of scientific research documents, whether they are published or not. The documents may come from teaching and research institutions in France or abroad, or from public or private research centers.
L'archive ouverte pluridisciplinaire HAL, est destinée au dépôt et à la diffusion de documents scientifiques de niveau recherche, publiés ou non, émanant des établissements d'enseignement et de recherche français ou étrangers, des laboratoires publics ou privés. 


\title{
Behavior modelling and microstructural evolutions of Ti-6Al-4V alloy under hot forming conditions
}

\author{
V. Velay ${ }^{\mathrm{a}, *}$, H. Matsumoto ${ }^{\mathrm{b}}$, V. Vidal ${ }^{\mathrm{a}}$, A. Chiba $^{\mathrm{c}}$ \\ ${ }^{a}$ Université de Toulouse; CNRS, Mines Albi, INSA, UPS, ISAE-SUPAERO ; ICA (Institut Clément Ader); \\ Campus Jarlard, F-81013 Albi, France \\ ${ }^{b}$ Department of Advanced Materials Science Faculty of Engineering, Kagawa University, 2217-20 Hayashi-cho, \\ Takamatsu, Kagawa 761-0396, Japan \\ ${ }^{c}$ Institute for Materials Research, Tohoku University, 2-1-1 Katahira, Aoba-ku 980-8577, Japan
}

\begin{abstract}
Ti-6Al-4V alloy is widely used in superplastic forming process. The conventional conditions require high forming temperatures $\left(T \geq 900^{\circ} C\right)$ and low strain rates $\left(\dot{\varepsilon} \leq 10^{-3} s^{-1}\right)$. In order to reduce the costs of the industrial process, recent investigations focus on the micro-structural refinement of the material. It allows an improvement of the forming conditions which makes lower forming temperatures and higher strain rates eligible whereas low strain rates $\left(\dot{\varepsilon} \leq 10^{-3} s^{-1}\right)$ and high temperatures $\left(T \geq 800^{\circ} C\right)$ are particularly suitable for conventional superplastic forming conditions. However, the mechanical response of the Titanium alloy strongly depends on the starting micro-structure considered and on its evolution with the temperature and the deformation. The objective of the present investigation is to observe the micro-structural evolutions of Ti-6Al-4V alloy under thermal and mechanical loadings from different starting micro-structures. Hence, an internal grain growth variable is identified by the use of these observations. Then, it is introduced into the behavior model and its influence on the mechanical response of the material is analysed. The final constitutive equations are able to take into account viscosity, strain hardening and grain size evolution for a wide range of strain rates and forming temperatures $\left(10^{-4} s^{-1} \leq \dot{\varepsilon} \leq 10^{-2} s^{-1} ; 650^{\circ} \mathrm{C} \leq T \leq 870^{\circ} \mathrm{C}\right)$. Moreover, the model is able to consider several starting microstructures (different initial grain sizes) and to predict their influence on the viscous flow and the strain hardening. At last, some model verifications are conducted to check the validity of the non-isothermal model formulation. Some predictions are also performed by considering several starting microstructures.

Keywords: Behavior modelling, Micro-structural evolutions, Viscoplastic material, Mechanical testing, Hot and superplastic forming conditions, Ti-6Al-4V alloy
\end{abstract}

\section{Introduction}

Ti-6Al-4V alloy is one of the most popular Titanium alloy, it is commonly used in superplastic forming process due to its high strength combined with an important ductility [1]. It exhibits a

\footnotetext{
*Corresponding author

Email address: vincent.velay@mines-albi.fr (V. Velay)
} 
very large amount of starting microstructures regarding different heat treatments and processing

5 practises. It can result lamellar, equi-axed or bi-modal microstructures. Moreover, combined heat treatments and mechanical processes also allow a grain refinement of the microstructure which is a well known method for enhancing the superplastic properties of Titanium alloys [2, 3]. Thus, lower temperature and higher strain rate conditions become eligible for superplastic deformation 4 , 5, 6, 7]. These test conditions strongly influence the mechanical behavior of the material. And

10 each particular starting microstructure may induce complex mechanisms as grain growth [8, 9, 10], dynamic recrystallization [11, 12, 13], cavity and void nucleation [14, 15, 16] in addition with grain boundary sliding [17], each mechanism respectively suggesting hardening, softening or damage.

The present work intends to analyse the thermo-mechanical behavior of Ti-6Al-4V alloy under hot forming conditions $\left(650^{\circ} \mathrm{C} \leq T \leq 870^{\circ} \mathrm{C}\right.$ and $\left.10^{-4} s^{-1} \leq \dot{\varepsilon} \leq 10^{-2} s^{-1}\right)$. It considers two different equi-axed starting microstructures with initial average $\alpha$ grain sizes of $0.5 \mu \mathrm{m}$ and $3 \mu \mathrm{m}$. Previous investigations show that void nucleation is not responsible for the necking phenomenon. Moreover, dynamic recrystallization can be assumed negligible whereas, in contrast, grain boundary sliding and grain growth have a preponderant role on the occurring flow stress and hardening [18, 19]. From these observations, constitutive equations are identified in order to consider the 20 influence of the starting microstructure and its evolution on the mechanical behaviour of Ti-6Al$4 \mathrm{~V}$ alloy. The grain growth effect is taken into account through the evolution laws of the literature [15, 20]. But, the law parameters have been identified for the temperature range investigated in the present study. Moreover, the results provided have been successfully compared with experimental observations. A part of them comes from the present work, another part is provided by the work of Semiatin [2, 21, 22] where the established law was extrapolated to our temperature and strain rate conditions. Hence, the grain growth evolution equations are introduced into the mechanical constitutive equations. The influence of the starting microstructure and its evolution is considered through a modification of the viscosity parameters of the model dependent on the initial grain size and on the grain growth. Moreover, a hardening variable depending on the grain size range is introduced and permits an accurate assessment of the stress increase. Afterwards, this approach is formulated under non isothermal conditions and a validation stage is performed at an intermediate test temperature and for different starting microstructures. Some model predictions are then possible in a range of grain sizes, temperature and strain rate conditions where any additional phenomenon occurs. At the end, the stability of the constitutive equations are analysed under 35 uni-axial conditions by predicting the reduction rate of the cross-sectional area of a specimen.

\section{Material and Methods}

Materials. Typical chemical composition for Ti-6Al-4V titanium alloy investigated in the present work is referred to table 1. Two different starting microstructures are considered, both of them consist of equiaxed $\alpha$ grains. They are produced using a combined forging-rolling process providing 


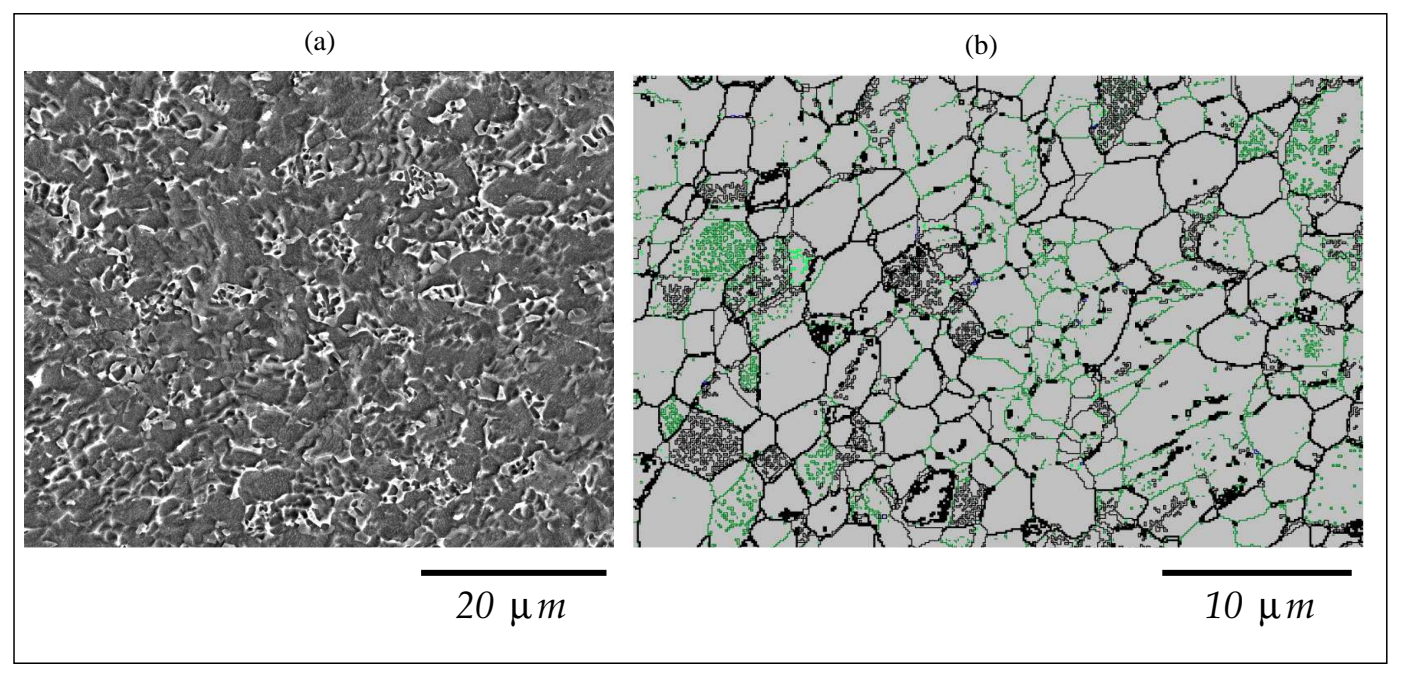

Figure 1: SEM image (a) and EBSD-grain boundary (b) of the starting microstructure with a grain size of $3 \mu m$

40 plates with a thickness between $1.4 \mathrm{~mm}$ and $3 \mathrm{~mm}$ and an Ultra Fine grain (UFG) microstructure with a mean $\alpha$ grain size of $0.5 \mu \mathrm{m}$ [18] and a Fine Grain microstructure (FG) with a mean $\alpha$ grain size of $3 \mu \mathrm{m}$ [23] respectively. Priorly, the first type of microstructure was solution treated at $1125^{\circ} \mathrm{C}$ for $3.6 \mathrm{ks}$, quenched in ice water to get an acicular $\alpha^{\prime}$ martensite microstructure and then hot-rolled to obtain a final UFG microstructure consisting of equiaxed $\alpha$ grains. The second type ${ }_{45}$ of micro-structure consists in $\alpha$ grain phase with small amounts of intergranular $\beta$ phase $(<10 \%)$.

Fig. 1 shows a SEM (a) and a EBSD-grain boundary (b) images of the starting microstructure with an initial grain size of $3 \mu m$.

\begin{tabular}{ccccc}
\hline $\mathrm{Al}$ & $\mathrm{V}$ & $\mathrm{O}$ & $\mathrm{N}$ & $\mathrm{Ti}$ \\
\hline 6.50 & 4.24 & 0.17 & 0.004 & Bal. \\
\hline
\end{tabular}

Table 1: General chemical composition wt.\%.

Microstructural Evolutions. Microstructures are identified by conducting Electron Back-Scatter Diffraction (EBSD) analysis and Scanning Electron Microscopy (SEM) observations [24]. It allows 50 the analysis of each starting microstructure but also its evolution with the temperature and the deformation. Indeed, in hot forming and superplastic forming processes, the control of grain growth is important and the grain size dynamically affects the viscoplastic flow of the material [25, 26], it can also acts on the hardening as discussed in the sequel. Thus, grain growth is investigated by conducting static and dynamic tests. The static tests consider different temperature exposure time regarding to the forming time during the process. In this case, no mechanical deformation is considered. The dynamic tests are based on high temperature tensile tests $\left(650^{\circ} \mathrm{C} \leq \mathrm{T} \leq 870^{\circ} \mathrm{C}\right)$ and consider different deformation conditions corresponding to several strain rates between $10^{-4} s^{-1}$ and $10^{-2} s^{-1}$. Fig. 2 and Fig 3 concern the starting microstructure with an initial $\alpha$ grain size of 

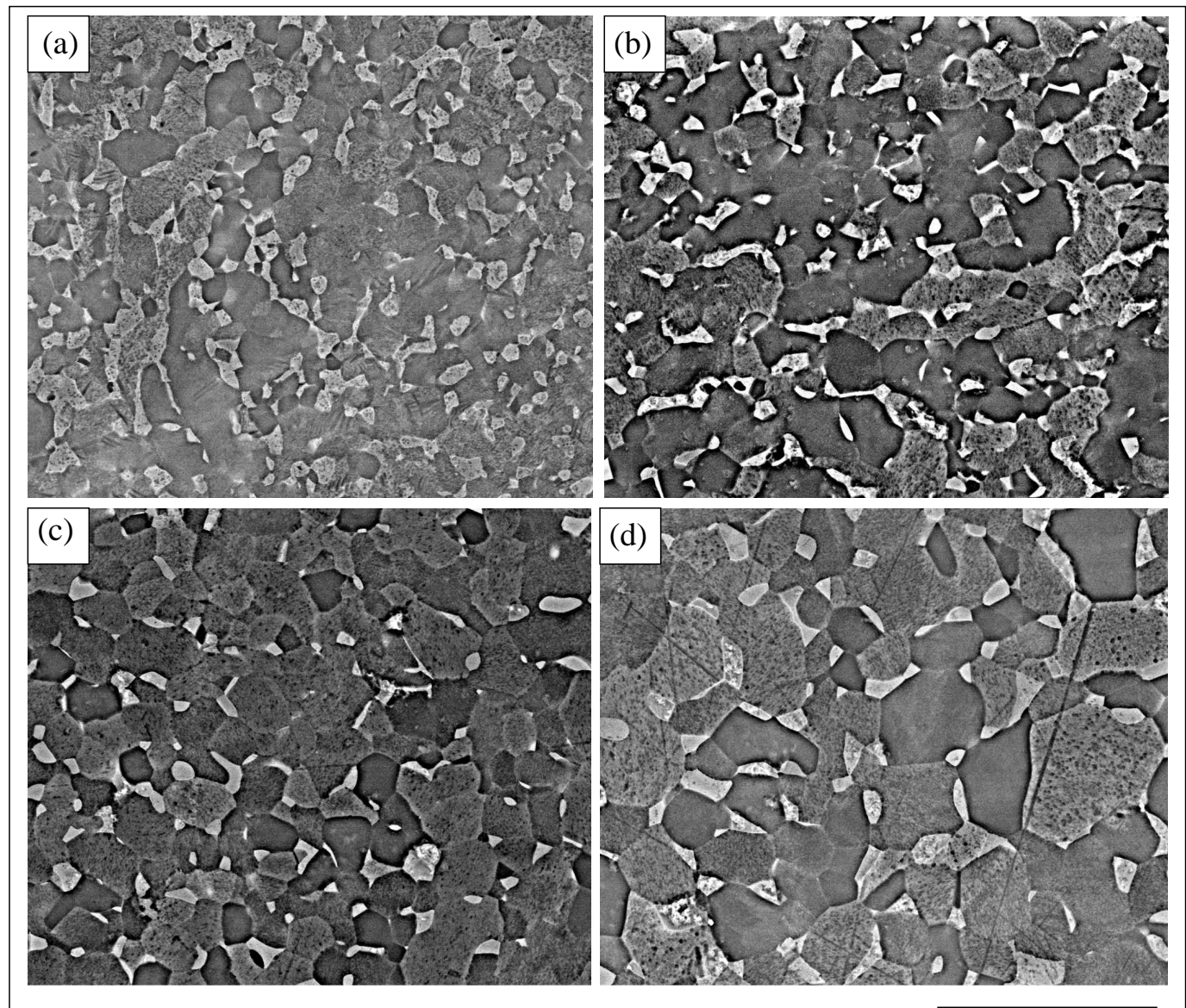

$20 \mu m$

Figure 2: Grain growth evolution observed by SEM micrographs (BSE mode) in the case of the static tests at $T=840^{\circ} \mathrm{C}$ and several temperature exposure times $t=1000 \mathrm{~s}(\mathrm{a}), t=5000 \mathrm{~s}(\mathrm{~b}), t=10000 \mathrm{~s}(\mathrm{c})$ and $t=30000 \mathrm{~s}(\mathrm{~d})$.

$3 \mu m$. Fig. 2 illustrates the grain growth evolution for the static tests at $T=840^{\circ} \mathrm{C}$ and several 60 temperature exposure times $(t=1000 \mathrm{~s}(\mathrm{a}), t=5000 \mathrm{~s}(\mathrm{~b}), t=10000 \mathrm{~s}(\mathrm{c})$ and $t=30000 \mathrm{~s}(\mathrm{~d}))$, whereas Fig. 3 shows the grain growth evolution in the case of the dynamic tests at $T=870^{\circ} \mathrm{C}$ and several strain rates $\left(\dot{\varepsilon}=10^{-2} s^{-1}(\mathrm{a}), \dot{\varepsilon}=10^{-3} \mathrm{~s}^{-1}\right.$ (b) and $\dot{\varepsilon}=10^{-4} \mathrm{~s}^{-1}$ (c)).

The results are compared with the works of Semiatin [21, 22, 27] regarding a Ti-6Al-4V titanium alloy with an initial grain size of $2.5 \mu \mathrm{m}$. In this study, several tests and observations allow to determine dynamic $\left(K=K_{d}\right.$, for a strain rate of $10^{-4} s^{-1}$ and $\left.10^{-3} s^{-1}\right)$ and static $\left(K=K_{s}\right)$ coarsening rate constants at $775^{\circ} \mathrm{C}$ and $815^{\circ} \mathrm{C}$ using the equation 1

$$
r^{3}=r_{0}^{3}+K t
$$

where $r$ and $r_{0}$ denoted the current and the initial average $\alpha$ grain radii respectively.

In the present work, this evolution law is slightly modified to consider not the radius but the diameter of the grain. Then, it is extended to the temperature range $650-870^{\circ} \mathrm{C}$ by defining 70 the evolution of the coarsening rate constants $\left\{K_{s}, K_{d 10^{-4} s^{-1}}, K_{d 10^{3} s^{-1}}\right\}$ versus temperature as an 


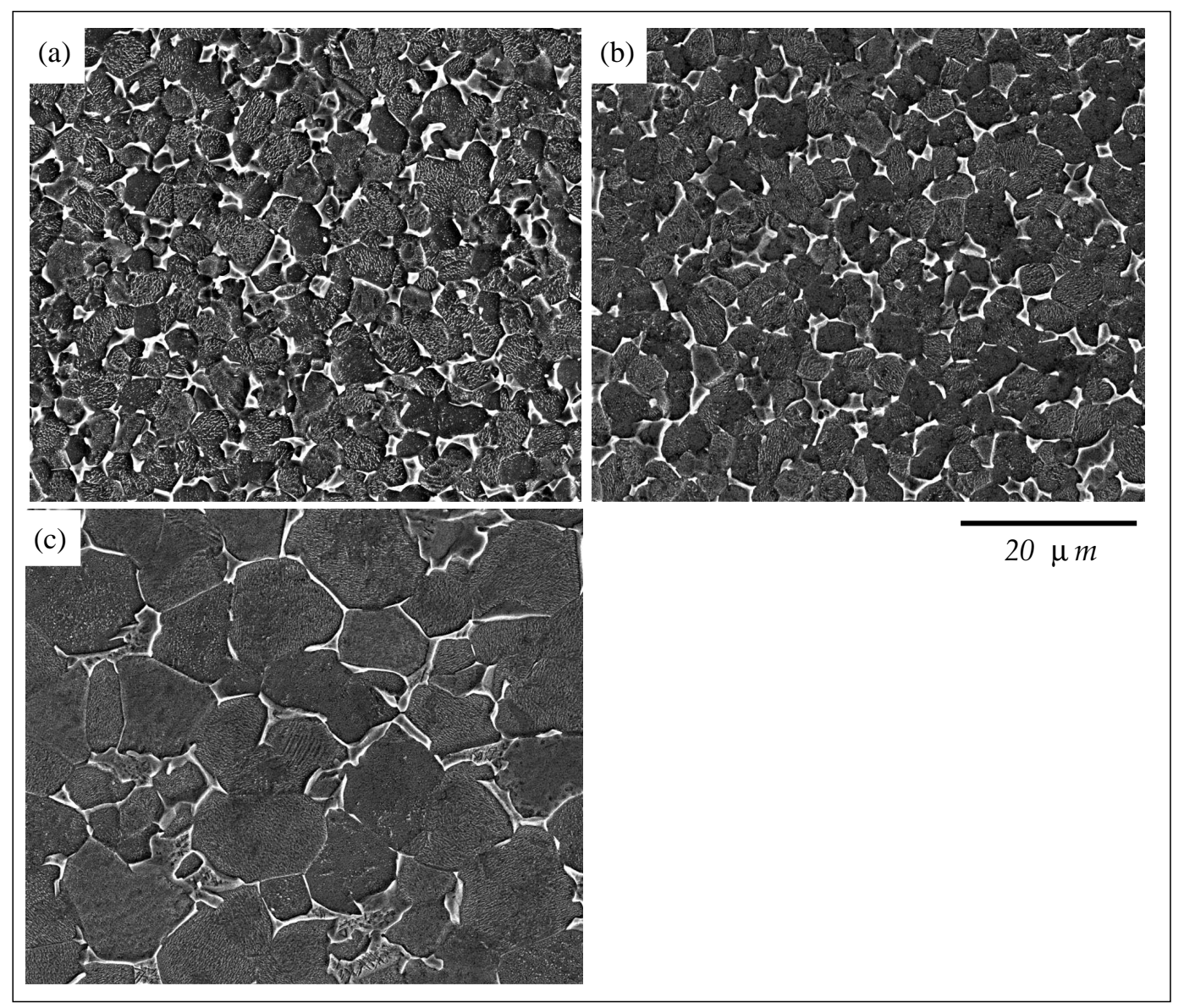

Figure 3: Grain growth evolution observed by SEM micrographs (SE mode) in the case of the dynamic tests at $T=870^{\circ} \mathrm{C}$ and several strain rates $\dot{\varepsilon}=10^{-2} \mathrm{~s}^{-1}$ (a), $\dot{\varepsilon}=10^{-3} \mathrm{~s}^{-1}$ (b) and $\dot{\varepsilon}=10^{-4} \mathrm{~s}^{-1}$ (c). 

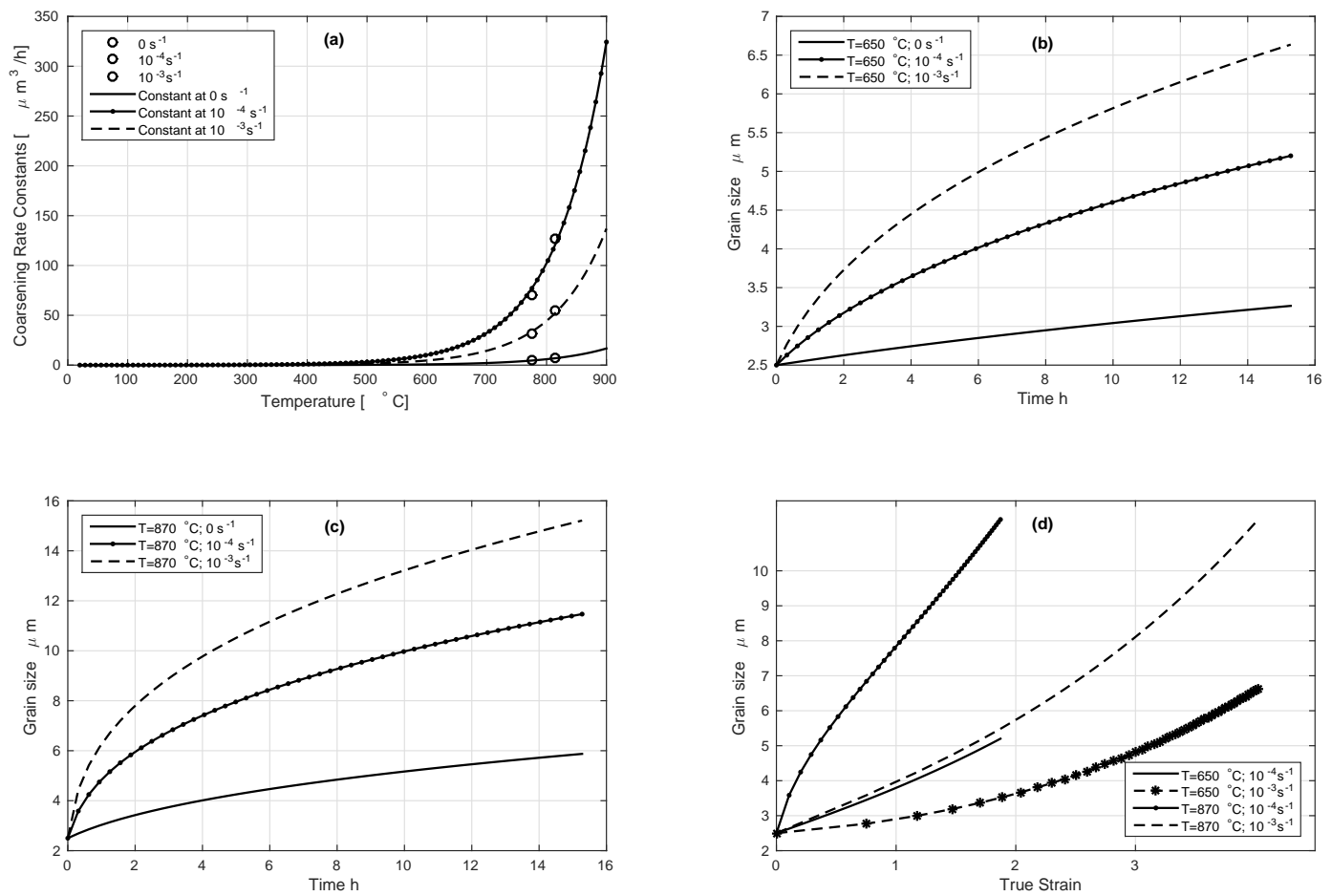

Figure 4: Identification of the coarsening rate constants based on the values provided by Semiatin et al at $775^{\circ} \mathrm{C}$ and $815^{\circ} \mathrm{C}$ and $\dot{\varepsilon}=\left\{0,10^{-4}, 10^{-3}\right\} s^{-1}$ (a); Simulated grain growth obtained with the identified values versus time
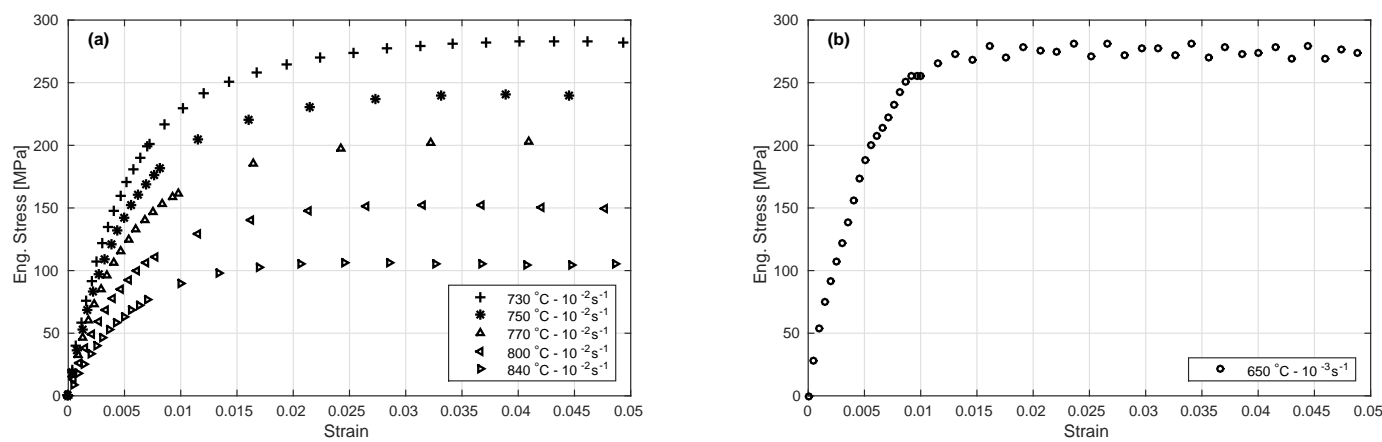

Figure 5: Tensile tests conducted under small deformation conditions at several temperatures and a strain rate of $10^{-2} s^{-1}$ (a); at $650^{\circ} \mathrm{C}$ and a strain rate of $10^{-3} s^{-1}$ (b)

exponential form (see Fig. 攼). Hence, grain growth can be simulated for different temperatures, different initial grain sizes and for strain rates of $\dot{\varepsilon}=\left\{0,10^{-4}, 10^{-3}\right\} s^{-1}$ as illustrated in Fig. $4(\mathrm{~b}-\mathrm{d})$.

High temperature tensile Testing for elastic properties. The elastic properties are assessed using tensile test under small deformation conditions (see Fig. 5). In order to obtain accurate values of the Young modulii, an extensometer is used to calculate the deformation. However, at these temperatures, the small values of the elasticity limits make these measurements difficult. Tab. 2 gives the values provided by the tensile tests. 


\begin{tabular}{lccccccc}
\hline$T\left\{{ }^{\circ} \mathrm{C}\right\}$ & 650 & 730 & 750 & 770 & 800 & 840 & 870 \\
\hline$E\{M P a\}$ & 70000 & 58000 & 50000 & 42000 & 30000 & 20000 & 15000 \\
\hline
\end{tabular}

Table 2: Evolution of the Young modulii with the test temperature

\begin{tabular}{|c|c|c|c|c|c|c|c|c|}
\hline$T^{\circ} \mathrm{C}$ & 650 & 700 & 730 & 750 & 770 & 800 & 840 & 870 \\
\hline$\dot{\varepsilon}=10^{-4} s^{-1}$ & $\checkmark x$ & $\checkmark x$ & $x$ & $\checkmark x$ & $x$ & $x$ & $x$ & $x$ \\
\hline$\dot{\varepsilon}=5.10^{-4} s^{-1}$ & $x$ & $\checkmark$ & $x$ & $\checkmark$ & & & & $x$ \\
\hline$\dot{\varepsilon}=10^{-3} s^{-1}$ & $\checkmark x$ & $\checkmark x$ & $x$ & $\checkmark x$ & $x$ & $x$ & $x$ & $x$ \\
\hline$\dot{\varepsilon}=5.10^{-3} s^{-1}$ & $x$ & $\checkmark$ & $x$ & $\checkmark$ & & & & $x$ \\
\hline$\dot{\varepsilon}=10^{-2} s^{-1}$ & $\checkmark x$ & $\checkmark x$ & $x$ & $\checkmark x$ & $x$ & $x$ & $x$ & $x$ \\
\hline
\end{tabular}

Table 3: Tensile test conditions, $\checkmark$ for an initial grain size of $d_{0}=0.5 \mu m$ and $\boldsymbol{x}$ for $d_{0}=3 \mu m$.

High temperature tensile Testing for superplastic properties. The mechanical tensile tests were so performed using a servo-hydraulic testing machine and a furnace accurate for the very large elongations. It includes three heating zones controlled by S-thermocouples and allows to maintain a constant temperature during all the sample deformation. As the use of a classical extensometer was not possible due to the very large elongation, a non linear crosshead displacement can be considered in order to obtain a constant target strain rate $\dot{\varepsilon}$ at the middle of the specimen [8, 28, 29$]$. However, it is important to notice that such a strain rate controlled test is only performed on the starting microstructure of $3 \mu \mathrm{m}$. Thus, in the case of the initial grain size of $0.5 \mu \mathrm{m}$, a constant cross head displacement is considered which induces a slight decrease of the target strain rate with the sample elongation. Regarding the definition of the tensile test conditions, the typical superplastic properties for Ti-6Al-4V alloy are enhanced at a temperature around $870^{\circ} \mathrm{C}$ and a strain rate between $10^{-4} \mathrm{~s}^{-1}$ and $10^{-3} \mathrm{~s}^{-1}$. The fine grain starting microstructure of $3 \mu \mathrm{m}$ is presently certified in the aircraft industry. Hence, the test conditions are defined to investigate the superplastic capabilities of an ultra fine grain microstructure of $0.5 \mu \mathrm{m}$ by decreasing the test temperature (forming temperature) and by increasing the strain rate. The test conditions considered for each starting microstructure have been selected to be close or similar in order to compare their strain-stress responses. Table 3 summarizes all the tensile test conditions.

Fig. 6 illustrates the strain-stress curves at different temperatures and strain rates. Fig. 6a-b shows the strain rate sensitivity induced at $750^{\circ} \mathrm{C}$ for both starting microstructures. As expected, the viscoplastic flow is greatly influenced by the starting microstructure and a decrease of the stress level with the grain size is observed whatever the test temperature. Moreover, Fig. [6 presents a decrease of the stress level at $\dot{\varepsilon}=\left\{10^{-2}, 10^{-3}\right\} \mathrm{s}^{-1}$ due to the necking of the specimen whereas the failure does not occur at the lower strain rate $\left(\dot{\varepsilon}=10^{-4} s^{-1}\right)$. A slight increase of the stress is observed due to the grain growth effect which initiates flow hardening into the 

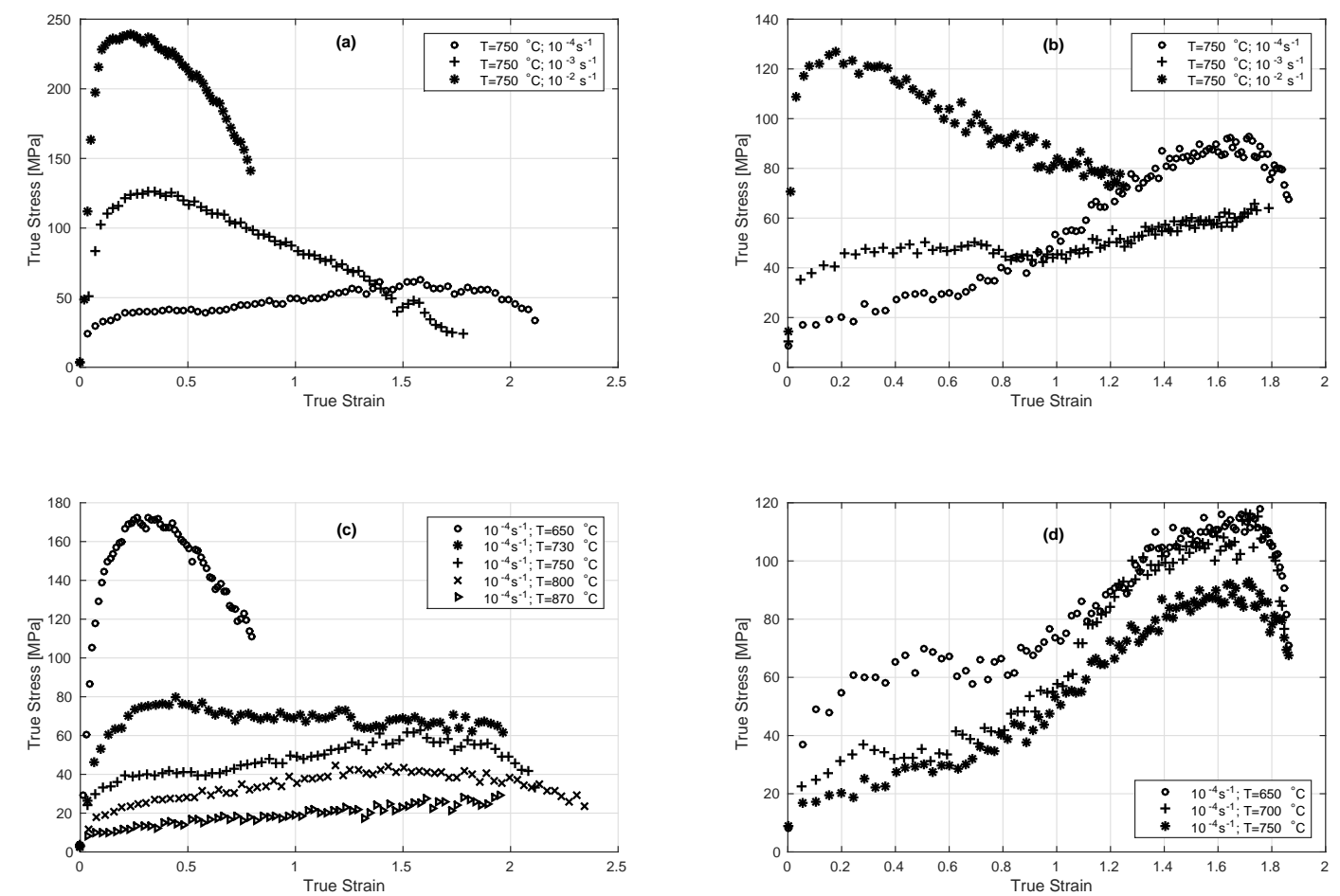

Figure 6: Strain rate sensitivity observed on experimental strain-stress curves at $750^{\circ} \mathrm{C}$ for both starting microstructures $d_{0}=3 \mu \mathrm{m}$ (a) and $d_{0}=0.5 \mu \mathrm{m}$ (b); Temperature effect observed on both starting microstructures $d_{0}=3 \mu \mathrm{m}$ (c) and $d_{0}=0.5 \mu \mathrm{m}(\mathrm{d})$.

material. Fig 6 s shows the same results for the initial grain size of $0.5 \mu m$. The decrease of the stress at the higher strain rate is not only due to necking but also to the loading rate which considers a constant cross head displacement as explained above. At the lower strain rates, flow behavior in steady state region indicates that grain boundary sliding occurs. Then, the pronounced flow hardening observed implies that deformation mode dynamically changes during straining and hardening becomes predominant certainly because of a grain growth effect (dislocation slips govern plastic deformation). Fig [6-d shows the temperature effect on the mechanical behavior for both starting microstructures at $10^{-4} \mathrm{~s}^{-1}$. The flow hardening is initiated at the higher temperature for the initial grain size of $3 \mu \mathrm{m}$, this effect significantly increases for the initial grain size of $0.5 \mu \mathrm{m}$.

\section{Modelling methods}

Grain Growth. The grain growth is defined as an internal variable of the behaviour model. In this section, the grain growth evolution based on the works of Semiatin (see Fig. 4) are used for the coefficient identification of the grain growth evolution law. Moreover, the results obtained are compared with the observations performed in the present study.

The grain size model which accounts for the effect of static and dynamic grain growth is 
illustrated by Eq2 [15, 26] .

$$
\dot{d}=\dot{d}_{s}+\dot{d}_{d}
$$

The static grain growth (Eq 3) describes the atomic diffusion process affected by temperature and related to the grain boundary mobility and boundary energy density [30, 31$]$.

$$
\dot{d}_{s}=A_{1} d^{-m_{1}}
$$

The dynamic grain growth (Eq. 4) allows to reproduce grain growth kinetics over a range of temperatures and strain rates $\underline{32}$ ].

$$
\dot{d}_{d}=A_{2} \dot{p}^{n_{1}} d^{-m_{2}}
$$

where $A_{i}, m_{i}(i=1,2)$ and $n_{1}$ are temperature dependent parameters and $p$ is the effective inelastic strain. In the sequel, $m_{1}=m_{2}=2$.

Eq. 24 have ever successfully applied on Ti-6Al-4V Titanium alloy at $900^{\circ} \mathrm{C}$ and $927^{\circ} \mathrm{C}$ [33, 34]. In the present work, Eq廿4 is slightly modified by introducing the parameter $n_{1}$ in order to better match with the experimental grain growth evolution provided by Semiatin [2, 22] and this study. The identification process of the model parameters was performed into two steps. First, the static and dynamic tests are considered separately (see Eq. 3(4). Second, it considers both equations simultaneously (see Eq 2) using the previous identified set of parameters as initial guess of the optimization problem. The parameters are determined using experimental curves provided by Semiatin law [2, 21, 27]. Fig. 7h-b and Fig. [7-d give the computed grain growth-time and the computed grain growth-strain curves respectively for each starting microstructure at different temperature levels. These results are compared, on the one hand, to the results provided by the Semiatin law 2] (used to identify the parameters) and, on the other hand, by the grain size measurements performed in the present study. The results obtained are in a very good agreement with experiment. Hence, the differential equations allow to simulate the static and dynamic grain growth for different starting microstructure, different temperature levels and different strain rates. Table 4 gives the parameters of the grain growth evolution with the temperature.

\begin{tabular}{lccccccc}
\hline$T\left\{{ }^{\circ} \mathrm{C}\right\}$ & 650 & 700 & 730 & 750 & 770 & 800 & 870 \\
\hline$A_{1} \times 10^{-13}\left\{\mathrm{~mm}^{3} . \mathrm{s}^{-1}\right\}$ & 1.24 & 2.01 & 2.71 & 3.31 & 4.05 & 5.46 & 10.75 \\
\hline$A_{2} \times 10^{-11}\left\{\mathrm{~mm}^{3} . \mathrm{s}^{-1+n_{1}}\right\}$ & 1.38 & 3.08 & 4.95 & 6.72 & 9.19 & 14.7 & 45 \\
\hline$n_{1}$ & 0.331 & 0.356 & 0.37 & 0.379 & 0.388 & 0.402 & 0.48 \\
\hline
\end{tabular}

Table 4: Temperature evolution of the identified parameters for the grain growth equations 

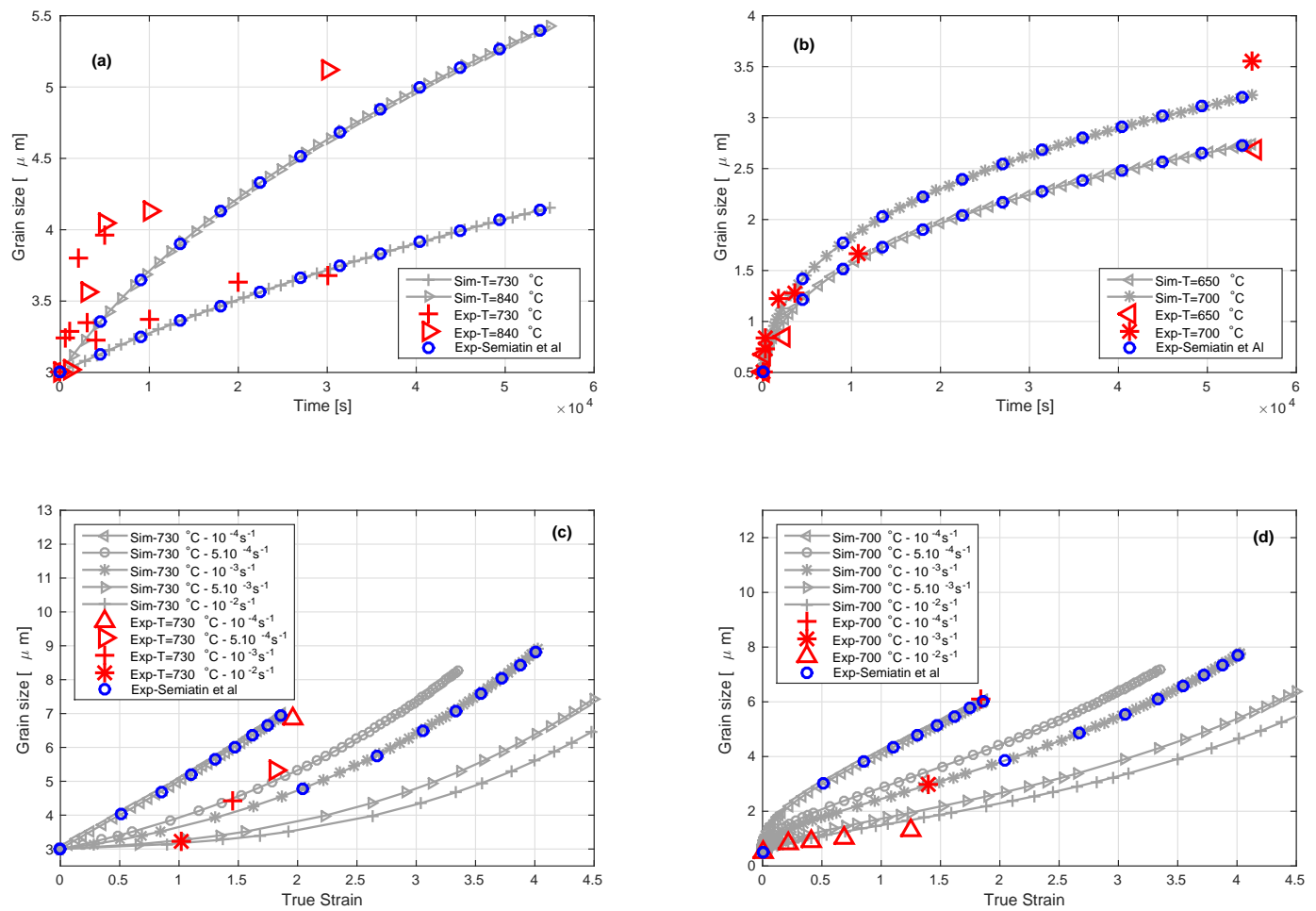

Figure 7: Comparison of computed grain growth-time (a,b) and computed grain growth-strain (c,d) curves using the evolution law identified with the coarsening rate constants by Semiatin et al and experimental measurements performed in the present work at $\{650,700\}^{\circ} \mathrm{C}$ and $d_{0}=3 \mu \mathrm{m}(\mathrm{a}, \mathrm{c})$; at $\{730,840\}^{\circ} \mathrm{C}$ and $d_{0}=0.5 \mu \mathrm{m}(\mathrm{b}, \mathrm{d})$

Unified Elasto-viscoplastic model. Unified constitutive equations for modelling the multiaxial superplastic and hot forming deformation can be formulated by assuming an energy dissipation potential $\Omega$. This thermodynamic framework has been adopted for many metallic materials [30, 35, 36, 37, 38, 39] under small as well under large deformation conditions [40], including the thermo-mechanical behavior of hot forming tools [41, 42]. The potential can be written as Eq. 5

The model formulation has to take into account the following considerations. On the one hand, superplastic forming conditions occur at low stress levels and long time periods inducing high temperature deformation process controlled by diffusion. On the other hand, hot forming conditions at higher stress levels and lower temperature coupled with high strain rates can be defined by a predominant dislocation controlled deformation. Thus, an accurate thermo-mechanical behavior model requires a coupling between the different induced mechanisms (lattice and grain boundary diffusion, grain boundary sliding and dislocation climb) [32].

$$
\Omega(f)=\left\langle\frac{f}{K}\right\rangle^{n} ; f=\sigma_{e q}-R-\sigma_{0}
$$

$K$ and $n$ define the viscous parameters able to describe the strain rate sensitivity of the material, $\sigma_{e q}=\sqrt{\frac{3}{2} S: S}$ and $S$ is the deviatoric part of the Cauchy stress $\sigma . \sigma_{0}$ is the yield stress and $R$ is an isotropic hardening variable related to the dislocation density in the plastic deformation. This variable is not significant under superplastic deformation mechanisms but can become predominant 
for the low temperatures or for an important grain growth. Its formulation is given by Eq. 6]

$$
R=Q\left(1-e^{-b p}\right)
$$

$p$ is the effective strain, $Q$ and $b$ are material parameters. Assuming normality and the associated flow rule, the multiaxial viscoplastic strain rates for materials implemented within a large strain deformation is given by Eq. 7 .

$$
D_{\boldsymbol{p}}=\frac{\partial \Omega}{\partial \boldsymbol{\sigma}}=\Omega^{\prime}(f) \frac{\partial f}{\partial \boldsymbol{\sigma}}=\frac{3}{2} \dot{p} \frac{S}{\sigma_{e q}}
$$

where $\dot{p}=\Omega^{\prime}(f)=\left\langle\frac{f}{K}\right\rangle^{n}=\sqrt{\frac{2}{3} D_{\boldsymbol{p}}: D_{\boldsymbol{p}}}$. Moreover, the corotational stress rate is given by Hooke's law (see Eq. 8).

$$
\stackrel{\nabla}{\boldsymbol{\sigma}}=2 G \boldsymbol{D}_{\boldsymbol{e}}+\lambda \operatorname{Tr}\left(\boldsymbol{D}_{\boldsymbol{e}}\right)
$$

in which $G=\frac{E}{2(1+\nu)}$ is the shear modulus defined by the Young modulus $E$ and the Poisson ratio $\nu$ as the lame elasticity constant $\lambda=\frac{E \nu}{(1-2 \nu)(1+\nu)}$. $D_{\boldsymbol{e}}$ is the rate of the elastic deformation which can be expressed as $D_{e}=D_{t}-D_{p}$ with $D_{t}$ is the rate of the total deformation.

The deformation gradient $\boldsymbol{F}$ can be defined together with the velocity gradient $\boldsymbol{L}$ and can be decomposed as the rate of the deformation tensor $\boldsymbol{D}$ and the spin tensor $\boldsymbol{W}$ as described in Eq. 9

$$
L=\dot{F} F^{-1}=D+W
$$

with $\boldsymbol{D}=\frac{1}{2}\left(\boldsymbol{L}+\boldsymbol{L}^{T}\right)$ and $\boldsymbol{W}=\frac{1}{2}\left(\boldsymbol{L}-\boldsymbol{L}^{T}\right)$.

Thus, the material stress rate can be expressed from the corotational stress rate, the spin tensor and the Cauchy stress (see Eq. 10).

$$
\dot{\sigma}=\stackrel{\nabla}{\sigma}+W \sigma-\sigma W
$$

Introduction of the grain growth effect on the viscosity and the hardening. As mentioned previously, the model formulation aims to take into account the initial grain size and its evolution with the temperature and the deformation. The initial grain size effect is introduced into the model formulation through the viscous parameters $K$ and $n$ as formulated in Eq. 11,

$$
K=K_{r}\left(\frac{d}{\chi\left(d_{0}\right)}\right)^{\frac{\mu}{n}} ; n=n_{r}\left(\frac{d}{\chi\left(d_{0}\right)}\right)^{\alpha}
$$


where $d$ is the average grain size of the grain growth model given by Eq. 204. $\mu$ and $\alpha$ are material constants which characterise the continuous material hardening due to grain growth. The

$$
Q=Q_{0} e^{\gamma \Delta d}
$$

where $\Delta d=d-d_{0}, Q_{0}$ and $\gamma$ are constant parameters. Thus, the hardening will be important for the significant increase of the grain size and reduced for a slight growth.

\section{Results and discussion}

Identification methodology. The identification of the model parameters is performed into 3 stages.

- The parameters identification of the grain growth model is first performed, the values $A_{1}$, $A_{2}, n_{1}, m_{1}$ and $m_{2}$ are determined.

- The parameters identification of the viscous law for each starting microstructure is performed without introducing the grain growth model, different values of $K$ and $n$ are identified for each starting microstructure. Constant values are considered for the parameters $Q$ and $b$ of the isotropic hardening variable.

- An unique set of parameters is adjusted, it describes the strain-stress response of both microstructures, $K_{r}, n_{r}, \mu, \alpha$ and $\chi\left(d_{0}\right)$ are determined in this stage.

- The introduction of the hardening due to the deformation mechanism change is added through the parameters $Q_{0}, \gamma$ and the hardening variable is modified.

The final mechanical parameters set is defined in table 5 , these values has to used in conjunction with the results provided in table 4.

The following parameters are set to be constant, $\mu=0.004, b=0.5, \chi_{0}=760$ and $\chi_{1}=0.03$.

Fig. 8 illustrates computed strain-stress curves compared to the experimental results at $650^{\circ} \mathrm{C}$ and $750^{\circ} \mathrm{C}$. Fig. 8 a does not show a deformation mechanism change for an initial grain size of $d_{0}=3 \mu m$ whereas this effect is observed and well assessed at low strain rate $\left(10^{-4} s^{-1}\right)$ for an initial grain size of $d_{0}=0.5 \mu m$ (Fig. $8 \mathrm{~b}$ ). This phenomenon increases with the temperature. At 


\begin{tabular}{lccccccc}
\hline$T\left\{{ }^{\circ} \mathrm{C}\right\}$ & 650 & 700 & 730 & 750 & 770 & 800 & 870 \\
\hline$\sigma_{0}\{\mathrm{MPa}\}$ & 10 & 8 & 6 & 5 & 4 & 3 & 0.2 \\
\hline$K_{r}\left\{\mathrm{MPa} . \mathrm{s}^{1 / n_{r}}\right\}$ & 1608 & 1750 & 1757 & 1700 & 1457 & 1250 & 1000 \\
\hline$n_{r}$ & 3.71 & 2.8 & 2.4 & 2.31 & 2.25 & 2.1 & 1.9 \\
\hline$\alpha$ & 0.128 & 0.095 & 0.088 & 0.08 & 0.764 & 0.0691 & 0.06 \\
\hline$Q_{0}\{\mathrm{MPa}\}$ & 5 & 6.9 & 8.4 & 9.5 & 10.6 & 12.5 & 17.2 \\
\hline$\gamma\left\{\mathrm{mm}^{-1}\right\}$ & 850 & 700 & 595 & 530 & 460 & 356 & 140 \\
\hline
\end{tabular}

Table 5: Temperature evolution of the identified parameters for the mechanical behavior model
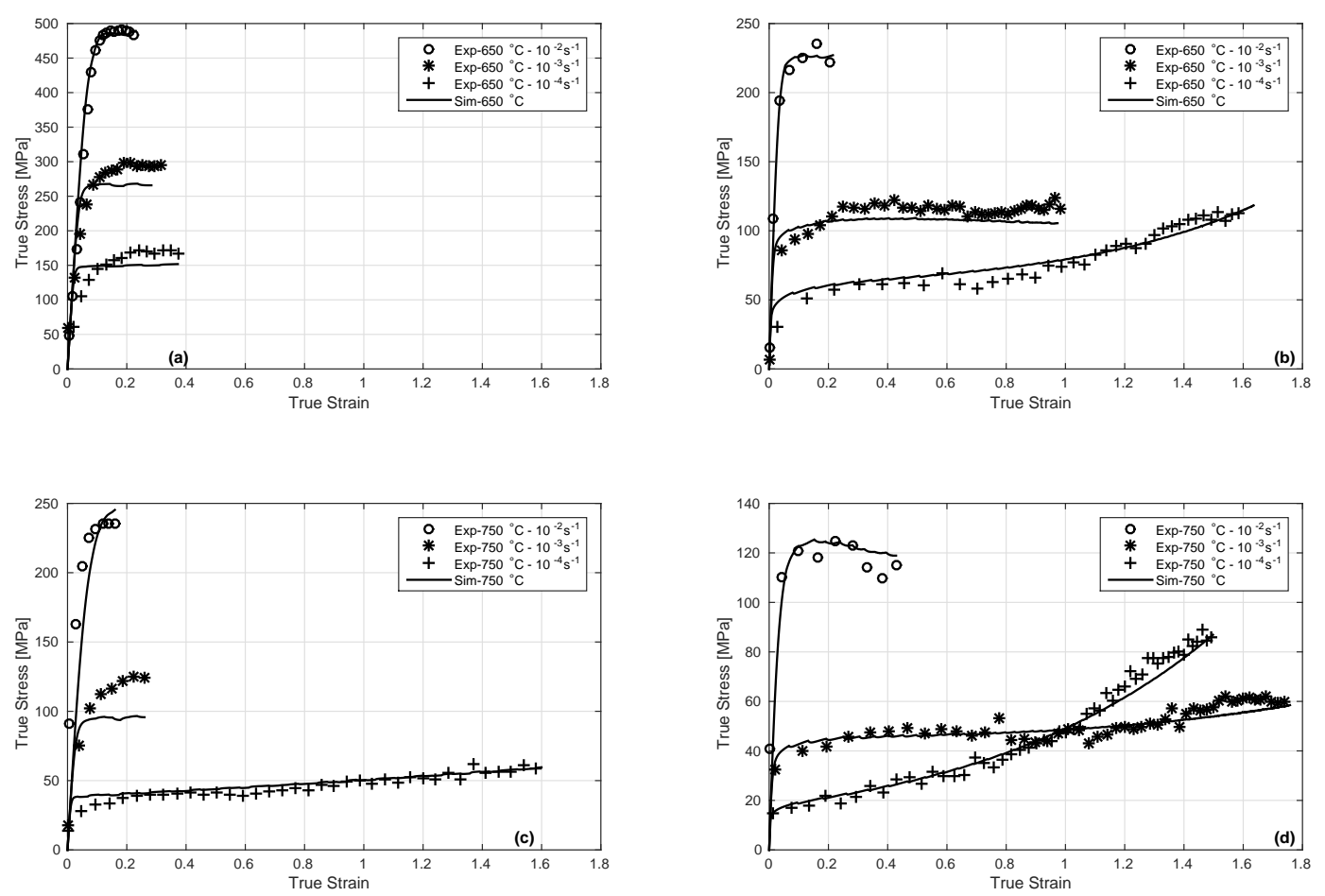

Figure 8: Computed Strain-Stress datas compared to Experimental results at a temperature of $650^{\circ} \mathrm{C}$ and an initial grain size of $d_{0}=3 \mu \mathrm{m}$ (a) and $d_{0}=0.5 \mu \mathrm{m}$ (b); at a temperature of $750^{\circ} \mathrm{C}$ and a initial grain size of $d_{0}=3 \mu \mathrm{m}$ (c) and $d_{0}=0.5 \mu \mathrm{m}(\mathrm{d})$.

$750^{\circ} \mathrm{C}$, a slight increase of the stress level is induced at the lower strain rate and for an initial grain size of $d_{0}=3 \mu \mathrm{m}$ (Fig. 8 ). Last, for the same test temperature, the rapid grain growth for an initial grain size of $d_{0}=0.5 \mu \mathrm{m}$ implies an increase of the hardening and an acceleration of the deformation mechanism changes at higher strain rate (Fig. $8 \mathrm{~d}$ at $10^{-3} s^{-1}$ ). These analyses are confirmed by Fig 9 where the hardening flow increases with the test temperature and it is all the more significant as a small initial grain size is considered. For the case of the starting of $0.5 \mu \mathrm{m}$, one can notice that the behavior model predicts a stress decrease under certain conditions (see Fig 8d at $\left.10^{-2} s^{-1}\right)$. It is due to the time-strain applied in the simulation inducing a slight strain rate decrease with the sample elongation as mentioned previously. 

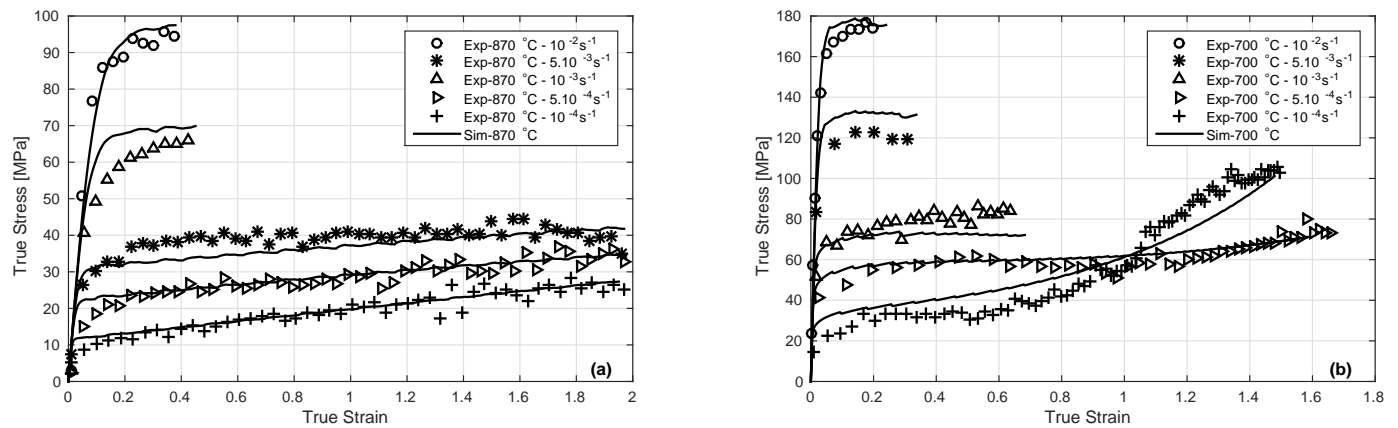

Figure 9: Computed Strain-Stress datas compared to Experimental results: (a) at a temperature of $870^{\circ} \mathrm{C}$ and an initial grain size of $d_{0}=3 \mu \mathrm{m}$ and (b) at a temperature of $700^{\circ} \mathrm{C}$ and a initial grain size of $d_{0}=0.5 \mu \mathrm{m}$.

Model verification. The evolutions of each model parameter with the temperature are addressed.

Thus, both non isothermal and isothermal loadings at intermediate temperature, but not used in the preliminary experimental database, can easily be simulated.

Table 6 gives the temperature evolution laws for each model parameters. The interpolation function coefficients are given in appendix 1 and their evolutions as well (see Table 7 and Fig. 13,[15).

\begin{tabular}{lccccc}
\hline Parameters & $\left(A_{i}, n_{1}, Q_{0}\right)$ & $E$ & $\sigma_{0}$ & $K_{r}$ & $\left(n_{r}, \gamma, \alpha\right)$ \\
\hline Considered laws & $a e^{b / T}$ & $\frac{a}{b+e^{c(T-d)}}$ & $\frac{a}{1+\left(\frac{T-b}{c}\right)^{2}}$ & $\frac{a}{b+e^{c(T-d)}}+e$ \\
\hline
\end{tabular}

Table 6: Temperature evolution laws for each model parameters

In order to verify the accuracy of the non isothermal model response, tensile tests are conducted at $T=840^{\circ} \mathrm{C}$ for both starting microstructures $\left(d_{0}=\{0.5,3\} \mu m\right)$. Computed and experimental strain-stress responses are compared. Fig. 10 shows that the obtained results are in a good agreement. For the case of the starting microstructure of $0.5 \mu \mathrm{m}$ at $10^{-2} \mathrm{~s}^{-1}$ (Fig. 10 $\mathrm{b}$ ), the model strain rate sensitivity associated with the non constant applied strain rate with the sample elongation can explain a part of the predicted stress decrease.

Fig 11 illustrates the capabilities of the behaviour model in the prediction of the strain-stress response at different temperatures and different starting microstructures.

Necking prediction. The stability of the previous constitutive equations is analysed under uniaxial loading [20, 31]. In the sequel, $A$ is the cross-sectional area of the sample and $P$ is the force applied. The incompressibility assumption under a superplastic deformation leads to the following expression for the reduction rate of the cross-sectional area (see Eq. 13).

$$
\frac{d A}{d t}=-A\left(\frac{P / A-R-\sigma_{0}}{K}\right)^{n}
$$



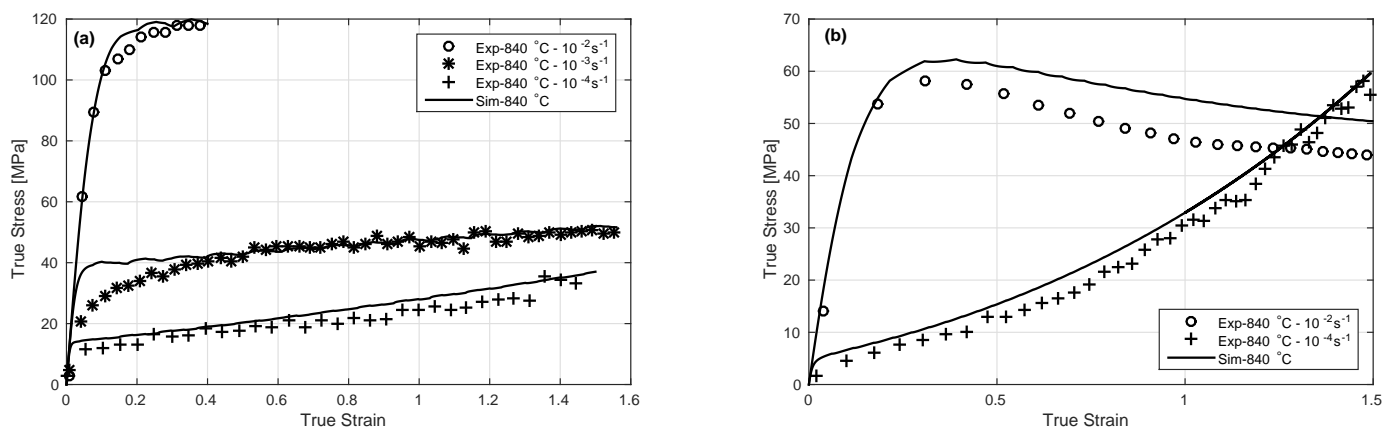

Figure 10: Computed Strain-Stress datas compared to Experimental results at a temperature of $840^{\circ} \mathrm{C}$ and an initial grain size of $d_{0}=3 \mu m(\mathrm{a})$ and $d_{0}=0.5 \mu m(\mathrm{~b})$
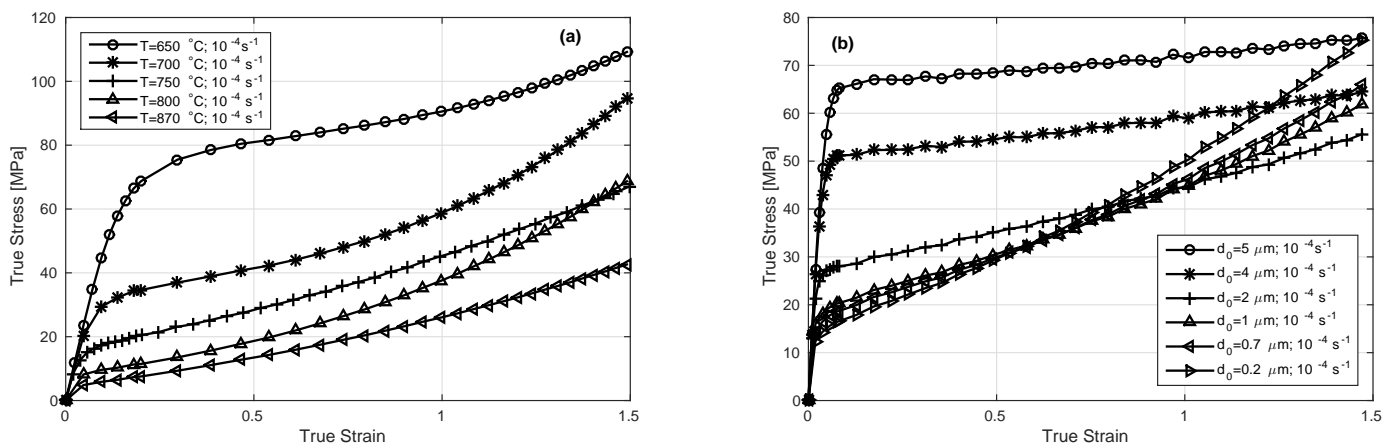

Figure 11: Model prediction for different test conditions (a) $d_{0}=0.5 \mu m$ and different temperatures; (b) at $T=750^{\circ} \mathrm{C}$ and different starting microstructures 
where $K$ and $n$ (see Eq11) and $R$ though the parameter $Q$ (see Eq. 12) depend on the grain growth $d$ and on the initial grain size $d_{0}$.

If the yield stress $\sigma_{0}$, the isotropic hardening $R$ and the grain growth $d$ are omitted, Eq. 13 can be reduced as Eq. 14.

$$
\frac{d A}{d t}=-A\left(\frac{P / A}{K_{0}}\right)^{n_{0}}
$$

where $K_{0}=K\left(d_{0}\right)$ and $n=n\left(d_{0}\right)$ are constant values for a fixed grain size $d_{0}$, in this case, these values only depend on the temperature.

An analytical solution can be determined for Eq14 whereas a numerical method is required to solve the Eq. 13, a Runge-Kutta method is used in the present work. Fig. 12 illustrates the shrinkage rate against the normalised cross-section area. Fig. 12 shows results at $750^{\circ} \mathrm{C}$ and an initial grain size of $0.5 \mu \mathrm{m}$, several initial stresses between $20 \mathrm{MPa}$ and $65 \mathrm{MPa}$ are considered related to several constant loads $P$. At the lower stress levels, the reduction rate of the cross-section area remains constant. It means that the shrinkage rate is not dependent on the cross section and necking is limited whereas at the higher stress levels, the shrinkage rate greatly increases as the cross-section decreases. It means that necking occurs leading to an elongation to failure [20]. Fig. $12 b$ (resp. Fig. 12k) gives the same observations at several temperatures and an initial grain size of $0.5 \mu m$ (resp. $3 \mu \mathrm{m}$ ). These figures show the influence of the strain rate parameter $n=1 / \mathrm{m}$ on necking where $m$ increases with the temperature. For the initial grain size of $0.5 \mu m$, the shrinkage rate remains constant with the cross-section reduction, it means that the local strain concentration is prevented and a large elongation is expected. This phenomenon is observed whatever the test temperature considered between $650^{\circ} \mathrm{C}$ and $750^{\circ} \mathrm{C}$. On the contrary, for an initial grain size of $3 \mu m$, a significant increase of the shrinkage rate is observed. For the same test conditions, an increase of the initial grain size leads to an increase of the $n$ parameter and a partial loss of the superplastic properties. On Fig. 12b-c, the dashed line illustrates the shrinkage rate against the cross-section reduction in the case where the hardening, the yield stress and the grain growth effects are neglected (see Eq. 14). In this case, a more important effect of the strain rate parameter $n$ is observed on the shrinkage rate. Thus, the introduction of the hardening and grain growth effects improves the superplastic properties and limits the necking [20]. 

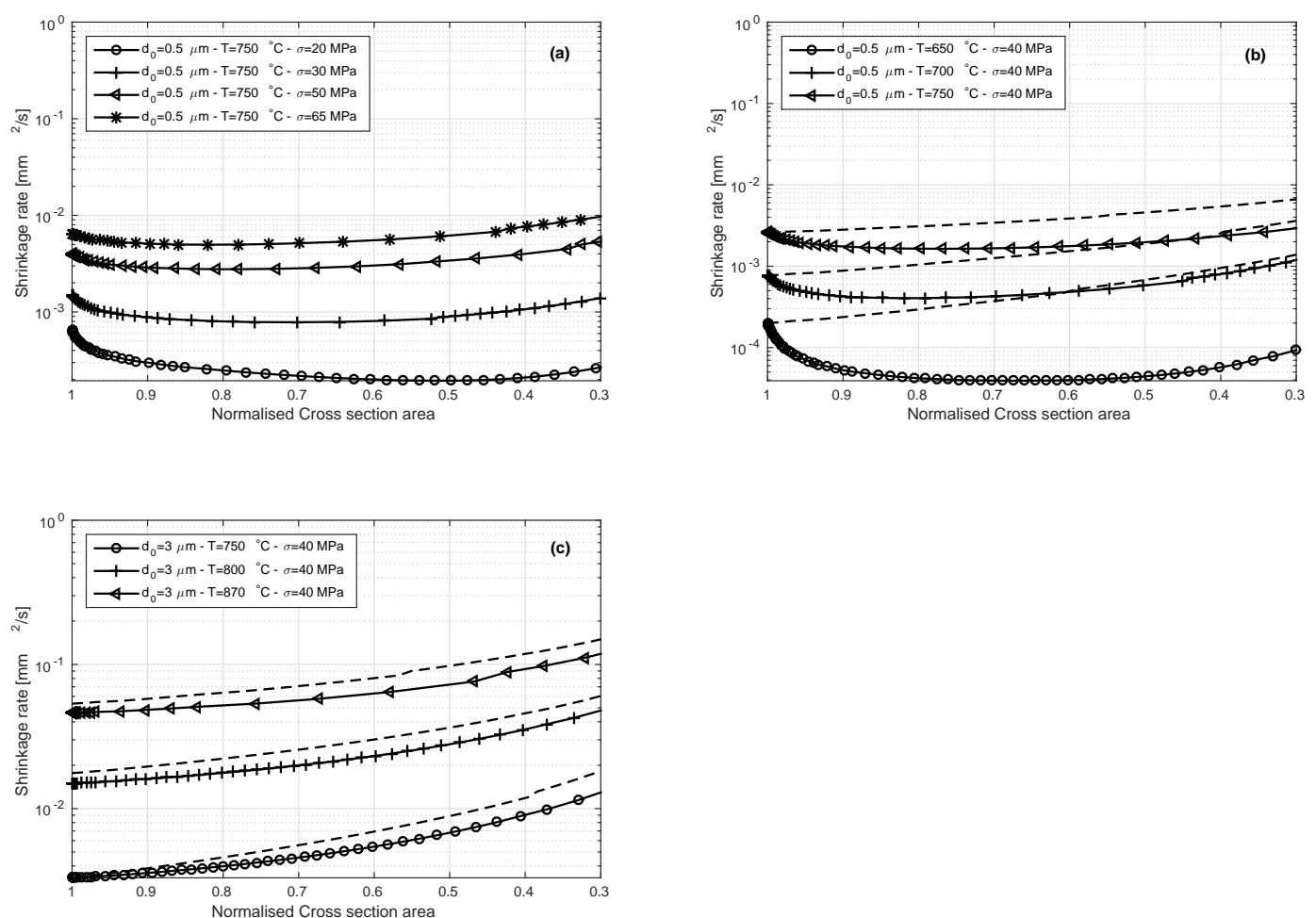

Figure 12: Shrinkage rate predicted against the normalised cross-section area at $750^{\circ} \mathrm{C}$, an initial grain size of $3 \mu \mathrm{m}$ and different stress levels (a); at different temperatures and an initial grain size of $0.5 \mu m(b)$; an initial grain of $3 \mu m$ (c); the dashed lines repreents the curves obtained when hardening, yield stress and grain growth are omitted. 


\section{Conclusions}

The following conclusions can be drawn from this work.

- The superplastic behaviour of Ti-6Al-4V Titanium alloy was investigated under hot forming conditions regarding both different starting microstructures with an average $\alpha$ grain size of $0.5 \mu \mathrm{m}$ and $3 \mu \mathrm{m}$. A temperature range $650^{\circ} \mathrm{C} \leq T \leq 870^{\circ} \mathrm{C}$ and strain rates between $10^{-4} s^{-1}$ and $10^{-2} s^{-1}$ were considered.

- The strain-stress response exhibits a viscous flow dependent on the test temperature, the initial microstructure and the grain growth.

- A strain hardening is observed for the long time period test due to the grain growth evolution.

- The parameters of a grain growth model are identified, it successfully describes the evolutions predicted by the works of Semiatin et al and the measurements performed in the present study.

- The internal variable related to grain growth was introduced into the mechanical model through the viscous flow and the hardening. The stability of the constitutive equations are investigated under uni-axial conditions by the prediction of the necking and by the analysis of the shrinkage rate against the normalised cross-sectional area.

- A non isothermal formulation of the model allows to accurately predict test conditions not considered in the identification process. Moreover, some predictions with different initial grain sizes are addressed.

\section{Acknowledgment}

This work was supported by the french region Midi Pyrénées. The authors would like to gratefully acknowledge the partners AIRBUS, PRODEM and AUROCK for their contributions. 


\section{Appendix}

\begin{tabular}{lccccc}
\hline Parameters & $\mathrm{a}$ & $\mathrm{b}$ & $\mathrm{c}$ & $\mathrm{d}$ & $\mathrm{e}$ \\
\hline$A_{1}$ & $1.406 .10^{-9}$ & -6252 & - & - & - \\
\hline$A_{2}$ & $1.19 .10^{-5}$ & -8921 & - & - & - \\
\hline$n_{1}$ & 0.993 & -719 & - & - & - \\
\hline$Q_{0}$ & 725 & -3254 & - & - & - \\
\hline$\alpha$ & 33.1 & -0.3 & $9.49 .10^{-3}$ & 10.9 & $5.01 .10^{-2}$ \\
\hline$\gamma$ & 549 & 0.469 & $1.2 .10^{-2}$ & 795 & - \\
\hline$\sigma_{0}$ & 156 & 0.223 & 0.024 & 550 & - \\
\hline$K_{r}$ & 1767 & 714 & 153 & - & - \\
\hline$n_{r}$ & 414 & 14.75 & 0.0175 & 345 & 1.95 \\
\hline
\end{tabular}

Table 7: Interpolation function coefficients of the model parameters with the temperature
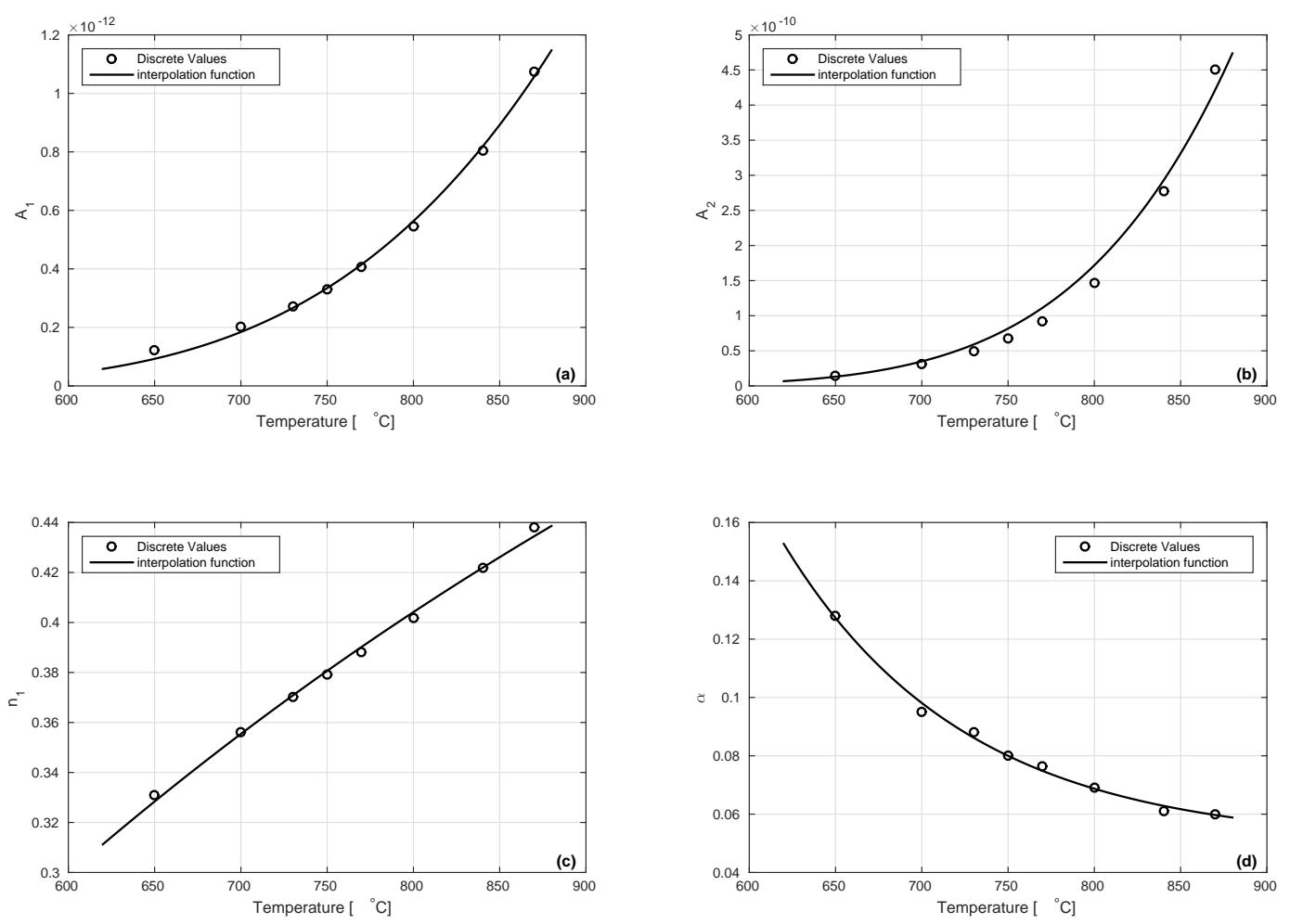

Figure 13: Evolution of the model parameters $A_{1}, A_{2}, n_{1}$ and $\alpha$ with temperature 

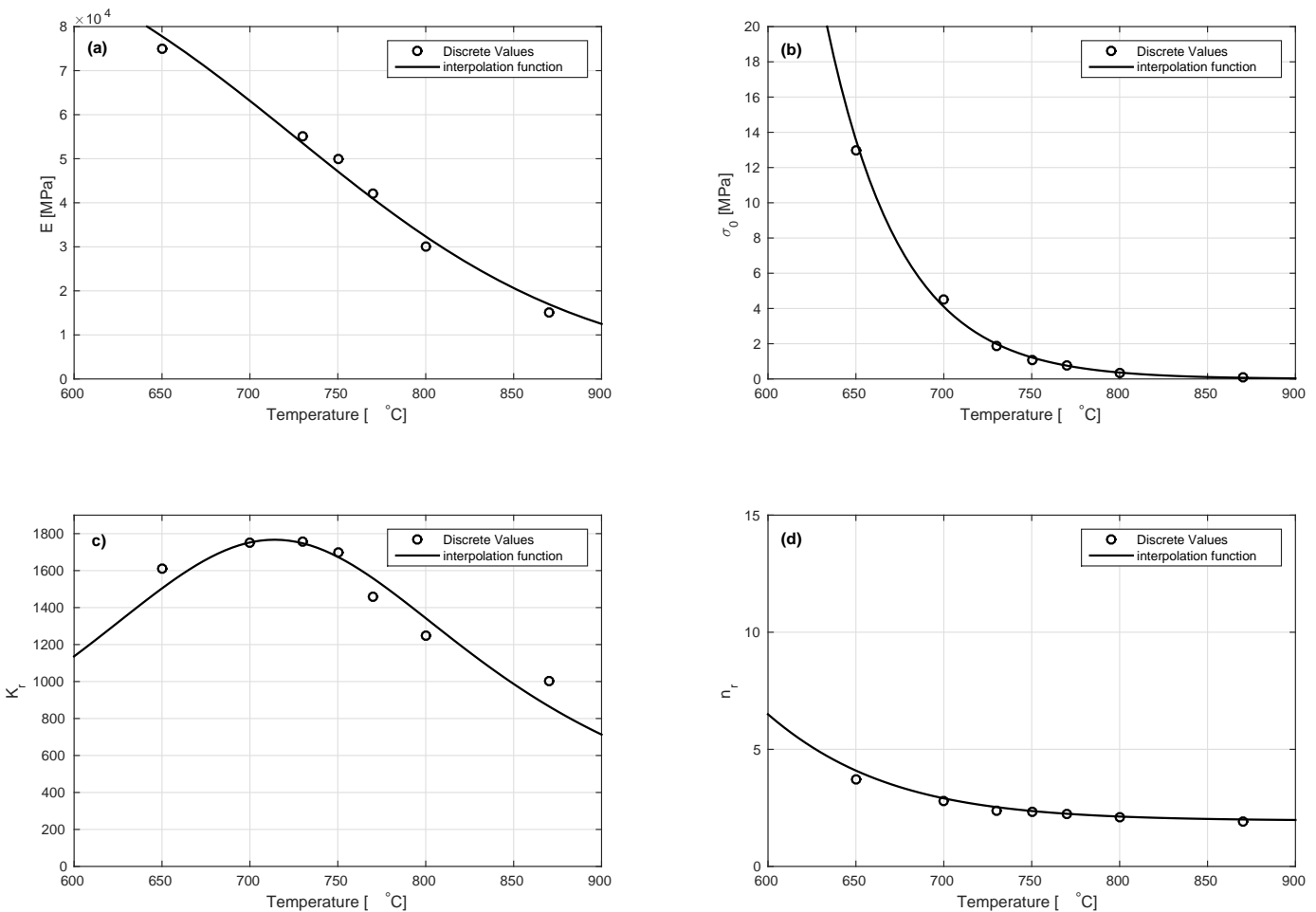

Figure 14: Evolution of the model parameters $E, \sigma_{0}, K_{r}$ and $n_{r}$ with temperature
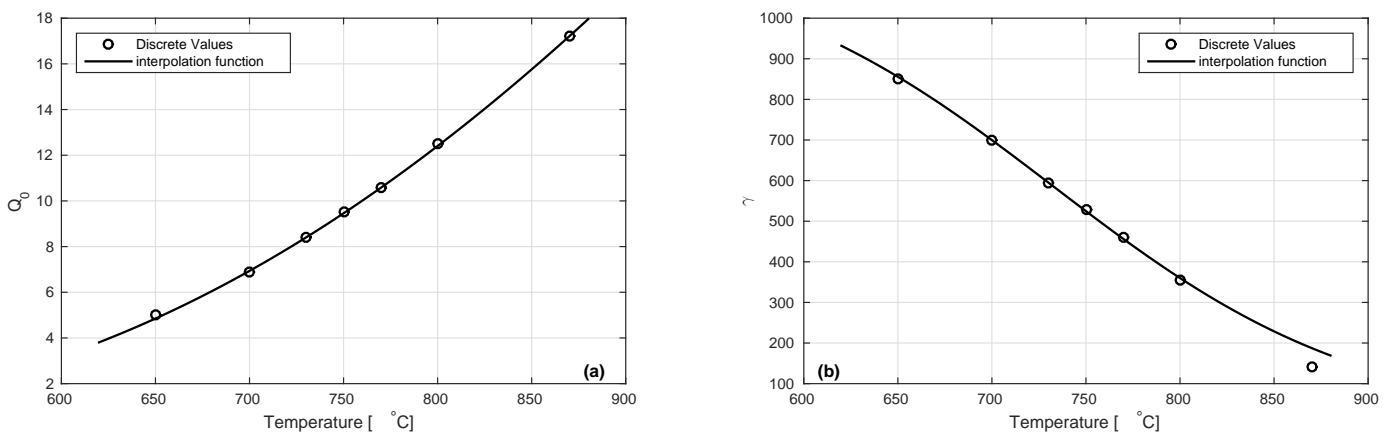

Figure 15: Evolution of the model parameters $Q_{0}$ and $\gamma$ with temperature 


\section{References}

[1] T. Langdon, Seventy-five years of superplasticity: historic developments and new opportunities, Journal of Materials Science 44 (22) (2009) 5998-6010.

[2] Y. Ko, C. Lee, D. Shin, S. Semiatin, Low-temperature superplasticity of ultra-fine-grained ti$6 \mathrm{al}-4 \mathrm{v}$ processed by equal-channel angular pressing, Metallurgical and Materials Transactions A 37 (2) (2006) 381-391.

[3] T. Zhang, Y. Liu, D. G. Sanders, B. Liu, W. Zhang, C. Zhou, Development of fine-grain size titanium 6al4v alloy sheet material for low temperature superplastic forming, Materials Science and Engineering: A 608 (2014) 265 - 272.

[4] C. Lee, S. Lee, J. Kim, Y. Chang, Mechanical and microstructural analysis on the superplastic deformation behavior of ti6al4v alloy, International Journal of Mechanical Sciences 42 (8) (2000) $1555-1569$.

[5] R. Mishra, V. Stolyarov, C. Echer, R. Valiev, A. Mukherjee, Mechanical behavior and superplasticity of a severe plastic deformation processed nanocrystalline Ti-6Al-4V alloy, Materials Science and Engineering: A 298 (12) (2001) $44-50$.

[6] Y. G. Ko, W. G. Kim, C. S. Lee, D. H. Shin, Microstructural influence on low-temperature superplasticity of ultrafine-grained ti6al4v alloy, Materials Science and Engineering: A 410411 (2005) 156 - 159, the Langdon Symposium: Flow and forming of Crystalline Materials.

[7] A. Sergueeva, V. Stolyarov, R. Valiev, A. Mukherjee, Enhanced superplasticity in a Ti-6Al-4V alloy processed by severe plastic deformation, Scripta Materialia 43 (9) (2000) 819 - 824.

[8] A. Ghosh, C. Hamilton, Mechanical behavior and hardening characteristics of a superplastic Ti-6Al-4V alloy, Metallurgical Transactions A-Physical Metallurgy and Materials Science 10 (6) (1979) 699-706.

[9] A. Ghosh, C. Hamilton, Microstructural chnages during superplastic forming of Ti-6Al-4V alloy, Journal of Metals 31 (12) (1979) 73.

[10] C. Johnson, S. Richter, C. Hamilton, J. Hoyt, Static grain growth in a microduplex Ti-6Al-4V alloy, Acta Materiala 47 (1) (1998) 23-29.

315 [11] Q. Bai, J. Lin, T. Dean, D. Balint, T. Gao, Z. Zhang, Modelling of dominant softening mechanisms for Ti-6Al-4V in steady state hot forming conditions, Materials Science and Engineering: A 559 (2013) $352-358$.

[12] L. Huang, L. Geng, A. Li, X. Cui, H. Li, G. Wang, Characteristics of hot compression behavior of Ti-6.5Al-3.5Mo-1.5Zr-0.3Si alloy with an equiaxed microstructure, Materials Science and Engineering: A 505 (12) (2009) $136-143$. 
[13] L. Huang, Y. Zhang, L. Geng, B. Wang, W. Ren, Hot compression characteristics of TiBw/Ti6Al4V composites with novel network microstructure using processing maps, Materials Science and Engineering: A 580 (2013) $242-249$.

[14] F. Dunne, I. Katramados, Micro-mechanical modelling of strain induced porosity under generally compressive stress states, International Journal of Plasticity 14 (7) (1998) 577 - 595.

[15] E. Alabort, D. Putman, R. Reed, Superplasticity in Ti-6Al-4V: Characterisation, modelling and applications, Acta Materialia 95 (2015) 428 - 442.

[16] J. Lin, B. Cheong, X. Yao, Universal multi-objective function for optimising superplasticdamage constitutive equations, Journal of Materials Processing Technology 125126 (2002) 199 -205 .

[17] V. Sinha, R. Srinivasan, S. Tamirisakandala, D. Miracle, Superplastic behavior of ti6al4v0.1b alloy, Materials Science and Engineering: A 539 (2012) 7 - 12.

[18] H. Matsumoto, V. Velay, A. Chiba, Flow behavior and microstructure in Ti6Al4V alloy with an ultrafine-grained -single phase microstructure during low-temperature-high-strain-rate superplasticity , Materials and Design 66, Part B (2015) $611-617$.

[19] B. Cheong, J. Lin, A. Ball, Modelling the effects of grain-size gradients on necking in superplastic forming, Journal of Materials Processing Technology 134 (1) (2003) 10 - 18.

[20] J. Lin, F. Dunne, Modelling grain growth evolution and necking in superplastic blow-forming, International Journal of Mechanical Sciences 43 (3) (2001) 595 - 609.

340 [21] G. A. Sargent, A. P. Zane, P. N. Fagin, A. K. Ghosh, S. L. Semiatin, Low-Temperature Coarsening and Plastic Flow Behavior of an Alpha/Beta Titanium Billet Material with an Ultrafine Microstructure, Metallurgical and Materials Transactions A - Physical Metallurgy and Materials Science 39A (12) (2008) 2949-2964.

[22] S. L. Semiatin, P. N. Fagin, J. F. Betten, A. P. Zane, A. K. Ghosh, G. A. Sargent, Plastic Flow and Microstructure Evolution during Low-Temperature Superplasticity of Ultrafine Ti6Al-4V Sheet Material, Metallurgical and Materials Transactions A - Physical Metallurgy and Materials Science 41A (2) (2010) 499-512.

[23] V. Velay, H. Matsumoto, L. Sasaki, V. Vidal, Investigation of the mechanical behaviour of Ti$6 \mathrm{Al}-4 \mathrm{~V}$ alloy under hot forming conditions: Experiment and modelling, Materialwissenschaft und Werkstofftechnik 45 (9) (2014) 847-853.

[24] J. Lee, Y. Song, D. Shin, C. Lee, Microstructural evolution during superplastic bulge forming of ti6al4v alloy, Materials Science and Engineering: A 243 (12) (1998) 119 - 125. 
[25] J. Lin, T. Dean, Modelling of microstructure evolution in hot forming using unified constitutive equations, Journal of Materials Processing Technology 167 (23) (2005) 354 - 362, 2005 International Forum on the Advances in Materials Processing Technology.

[26] B. Cheong, J. Lin, A. Ball, Modelling of hardening due to grain growth for a superplastic alloy, Journal of Materials Processing Technology 119 (13) (2001) 361 - 365, international Conference on Advances in Materials Processings Technology.

[27] S. L. Semiatin, G. A. Sargent, Constitutive Modeling of Low-Temperature Superplastic Flow of Ultrafine Ti-6Al-4V Sheet Material, in: Sanders, DG (Ed.), Superplasticity in Advanced Materials, Vol. 433 of Key Engineering Materials, Univ Washington, Dept Mech Engn \& Educ Outreach Program; ICSAM 2009 Comm, 2010, pp. 235-240, 10th International Conference on Superplasticity in Advanced Materials, Seattle, WA, JUN 29-JUL 02, 2009.

[28] W. Pan, M. Krohn, S. Leen, T. Hyde, S. Walloe, A sigmoidal model for superplastic deformation, Journal of Materials Design and Applications 219 (L3) (2005) 149-162.

[29] P. N. Comley, ASTM E2448 - A unified test for determining SPF properties, Journal of Materials Engineering and Performance 17 (2) (2008) 183-186, International Symposium on Superplasticity and Superplastic Forming, Baltimore, MD, JUN 25-28, 2007.

[30] F. Dunne, Inhomogeneity of microstructure in superplasticity and its effect on ductility, International Journal of Plasticity 14 (4-5) (1998) 413-433.

[31] J. Lin, Selection of material models for predicting necking in superplastic forming, International Journal of Plasticity 19 (4) (2003) $469-481$.

[32] J. Cao, J. Lin, A study on formulation of objective functions for determining material models, International Journal of Mechanical Sciences 50 (2) (2008) 193 - 204.

[33] T. Kim, F. Dunne, Determination of superplastic constitutive equations and strain rate sensitivities for aerospace alloys, Journal of Aerospace Engineering 211 (G6) (1997) 367-380.

[34] M. Zhou, F. Dunne, Mechanisms-based constitutive equations for the superplastic behaviour of a titanium alloy, Journal of Strain Analysis for Engineering Design 31 (3) (1996) 187-196.

[35] J. L. Chaboche, A review of some plasticity and viscoplasticity constitutive theories, International Journal of Plasticity 24 (10) (2008) 1642-1693.

[36] G. Cailletaud, K. Sai, Study of plastic viscoplastic models with various inelastic mechanisms, International Journal of Plasticity 11 (8) (1995) 991-1005.

[37] M. Khraisheh, H. Zbib, C. Hamilton, A. Bayoumi, Constitutive modeling of superplastic deformation - Part I: Theory and experiments, International Journal of Plasticity 13 (1-2) (1997) 143-164. 
[38] M. Khaleel, K. Johnson, C. Hamilton, M. Smith, Deformation modeling of superplastic AA5083, International Journal of Plasticity 14 (10-11) (1998) 1133-1154.

[39] A. Vanderhasten, L. Rabet, B. Verlinden, Ti-6Al-4V: Deformation map and modelisation of tensile behaviour, Materials and Design 29 (6) (2008) 1090-1098.

[40] F. Dunne, I. Katramados, Large deformation compressiontorsion behaviour of a titanium alloy and its modelling, International Journal of Mechanical Sciences 40 (9) (1998) 901 - 912.

[41] V. Velay, G. Bernhart, L. Penazzi, Cyclic behavior modeling of a tempered martensitic hot work tool steel, International Journal of Plasticity 22 (3) (2006) 459-496.

[42] V. Velay, T. Cutard, N. Guegan, Thermal behaviour modelling of superplastic forming tools, Materialwissenschaft und Werkstofftechnik 43 (9, SI) (2012) 799-804. 